\title{
Epidemiological Patterns of AIDS in a Reference Center from Catanduva, São Paulo State, Brazil ${ }^{*}$
}

\author{
Arlindo Schiesari Jr. ${ }^{1,2}$, Kátia Jaira Galisteu ${ }^{3}$, Luciana Ventura Cardoso ${ }^{3}$, \\ Vanessa Maria Brogio Schiesari ${ }^{2}$, Adriana Antônia da Cruz Furini ${ }^{4}$, \\ Andrea Regina Baptista Rossit ${ }^{5}$, Ricardo Luiz Dantas Machado ${ }^{3 \#}$ \\ ${ }^{1}$ Integrated College Padre Albino, Catanduva, Brazil \\ ${ }^{2}$ STD/AIDS Municipal Program, Catanduva, Brazil \\ ${ }^{3}$ Department of Dermatology, Parasitic and Infectious Diseases, Medicine School in São José do Rio Preto, \\ São José do Rio Preto, Brazil \\ ${ }^{4}$ Rio Preto University Center, São José do Rio Preto, Brazil \\ ${ }^{5}$ Biomedical Institute, Microbiology and Parasitical Diseases from Fluminense Federal University, Niteroi, Brazil \\ Email: " ricardomachado@famerp.br
}

Received March 21, 2012; revised May 6, 2012; accepted May 21, 2012

\begin{abstract}
Objective: Hereby we present the epidemiological and clinical profile of HIV-infected population before and during the highly active antiretroviral therapy (HAART) era from a tertiary care hospital in the Southeastern region of Brazil. Methods: A retrospective, cross-sectional and descriptive study was carried out, this involved the analysis of the medical records of patients diagnosed with HIV-1/AIDS admitted to Hospital Escola Emílio Carlos, located in the municipality of Catanduva, State of São Paulo, Brazil. Results: In both pre-HAART and HAART periods, HIV-1 infection was more prevalent in men. Heterosexuality and secondary education were associated with AIDS in the HAART period. Statistically significant association was only observed for co-infection with HIV-1/Hepatitis C in the pre-HAART era and the number of patients with opportunistic infection (OI) was lower in the HAART period. Among all OI it is worth mentioning pulmonary pneumocystosis, which despite being common in two periods, its occurrence was considerably greater in the pre-HAART era. Concerning the distribution of OIs according to the HIV-1 viral load and serial count of $\mathrm{T} \mathrm{CD} 4^{+}$lymphocytes, a significant association was observed. The association between the number of deaths by OIs and death in the 1st year of diagnosis in the HAART treatment was significant. Conclusions: The clinical and epidemiological profile of a specialized HIV-1/AIDS center in Catanduva, Southeastern Brazilian region, is consistent with the epidemiology of AIDS in the country.
\end{abstract}

Keywords: HIV-Infected Population; Antiretroviral Therapy Highly Active; Brazil

\section{Introduction}

Almost 30 years after the beginning of the AIDS epidemic, human immunodeficiency virus- 1 infection (HIV-1) is still a serious world health problem. An estimated 33.4 million people around the world carry the virus, and, in 2008 alone, there were 2 million AIDS-related deaths [1]. Despite these alarming statistics, the highly active antiretroviral therapy (HAART), which has been available since 1996, has revolutionized the treatment of HIV-1 infection and allowed the control of the disease in the long term, signifycantly reducing the frequency of OI and death related AIDS [2,3]. However, even in the HAART era, the fre-

\footnotetext{
*Municipal Program of Sexually Transmissible Diseases/AIDS, Faculdades Integradas Padre Albino-FIPA and Faculty of Medicine from São José do Rio Preto-FAMERP.

"Corresponding author.
}

quency of AIDS-related OI still impacts morbid-mortality in the HIV-1 infected population [4].

In Latin America one-third of all HIV-1-positive individuals reside in Brazil, a country that 544,846 AIDS cases were notified from 1980 to 2009, and approximately $60 \%$ of these cases occurred in the Southeastern region of the country $[5,6]$. Current statistics indicate the occurrence of significant epidemiological changes in the HIV-1 infection epidemic in Brazil, where the dissemination of the disease has increased in small urban centers in individuals with heterosexual practice and in people with low education [6-9]. In 1996, the country has drawn worldwide attention for its decision of making HAART available to all AIDS patients, which has substantially contributed to reduce mortality and increase the survival rate of the referred population [10], according to the international standard. 
Despite the access to HAART, AIDS-related diseases are still important causes of death in some regions of the country, especially OI, such as pulmonary pneumocystosis and tuberculosis [11-14]. The city of Catanduva, located in the Southeastern Brazil is among the $100 \mathrm{mu}-$ nicipalities with the greatest incidence of AIDS cases in the country [6]. Nevertheless, there is no clinical and epidemiological characterization of individuals with HIV/ AIDS in this city, which may impact the design and implementation of health policies tailored to this area. We present the epidemiological and clinical profile of the $\mathrm{HIV}$-infected patients before and during the HAART era from a tertiary care hospital in Southeastern Brazilian region.

\section{Material and Methods}

A retrospective, cross-sectional and descriptive study was carried out. This involved the analysis of the medical records of patients diagnosed with HIV-1/AIDS admitted to Hospital Escola Emílio Carlos, located in the municipality of Catanduva, State of São Paulo, Brazil. This hospital is a philanthropic tertiary care facility associated with the medical and nursing schools of Faculdades Integradas Padre Albino. It offers treatment for several medical conditions, including infectious and contagious diseases, on outpatient and inpatient bases. Catanduva has 114,812 inhabitants and is located $380 \mathrm{~km}$ from the State capital. In the present study, the medical records of patients 18 years or older diagnosed with infection by HIV-1/ AIDS and residing in of Catanduva were examined. Two different periods were selected and simultaneously investigated: the pre-HAART period (from January 1991 to December 1995) and the HAART period (from January 2002 to December 2009), which corresponds to before and after more potent drugs have become available in Brazil. Of the total 633 individuals diagnosed with HIV-1/ AIDS infection in the two periods of the study, 302 patients records were selected, 65 from the pre-HAART period and 237 from the HAART period. The other records (especially from the pre-HAART period) were not available for the study. The protocol for this study was reviewed and approved (Process number 235/2006) by the ethical and Research Board of the Faculty of Medicine from São José do Rio Preto, São Paulo state, Brazil.

In order to collect the data from the patients records, a standard form containing the following items was used: age, gender, marital status, reason for patient admission to the health care unit, area of residence (rural or urban), education, possible HIV mechanism of transmission, date of diagnosis of HIV-1 infection, serial count of T CD4 ${ }^{+}$ lymphocytes, and HIV-1 viral load in the medical care delivered to the patient as soon as he/she was admitted to hospital. Data on co-infection with hepatitis B or C, iden- tification and frequency of AIDS-defining opportunistic illnesses (OI), serial count of $\mathrm{LT} \mathrm{CD}^{+}$and VL in the presence of OI, the dates of death, survival from the diagnosis of HIV-1 infection until death, and the identification and frequency of the OI that caused death were also collected. Besides, the antiretroviral treatment and therapeutic adherence by individuals who died from the OI in the HAART era were evaluated. Good compliance with the antiretroviral therapy, patient attendance for previously scheduled medical appointments and collection for laboratory testing were considered therapeutic adherence criteria.

Analyses were performed using $\mathrm{R}$ statistical software version 2.4.1 (The R Foundation for Statistical Computing ISBN 3-900051-070, http://www.r-project.org, Vienna, Austria). To obtain the independence among proportions, we applied the v2 test or the Fisher exact test. The selected significance level for statistical inference was $5 \%$.

\section{Results}

Of the 302 selected patients' medical records, 65 were from the pre-HAART period (from January 1991 to December 1995) and 237 were from the HAART period (from January 2002 to December 2009. The mean age was 37.5 years old for patients form the pre-HAART period and 41.3 years old for those patients in the HAART period. In both periods, HIV-1 infection was more prevalent in men $(75.4 \%$ and $59.9 \%$ in pre-HAART and HAART periods), but there has been a considerable increase in the infection rate among women in the HAART period $(P=0.03)$. Concerning the patients education, there have been significantly higher infection rates between people with secondary education during the HAART period ( $P=0.001)$. Analysis of patient admission to the out patients clinic health care center reveals that less patients sought health services in the HAART period $(P=0.04)$. When compared to the possible ways of getting HIV-1 in the two periods, heterosexuality was the main risk fact for acquisition of the disease in the HAART period $(P<0.001)$, whereas bisexuality and use of injectable drugs (UID) were statistically significant high risk factors in the pre-HAART period ( $P=0.03$ and $P<0.0001$, respectively). No association was observed between prevalence of the infection and marital status and residence area (rural versus urban) of these patients.

In the pre-HAART period, 24 of 65 patients' records with information on serial count of $\mathrm{T} \mathrm{CD} 4^{+}\left(\mathrm{LT} \mathrm{CD} 4^{+}\right)$ lymphocytes and HIV-1 (CV HIV-1) viral load when the patients were first admitted to hospital. Ten patients (41.6\%) had LT CD4 ${ }^{+}$count $<200$ cells $/ \mathrm{mm}^{3}$ and nine (37.5\%) had CV HIV-1 higher than 100,000 copies/ml. 
In the HAART era 212 of 237 had the same information patients'. Ninety-one patients $(42.9 \%)$ had LT CD4 ${ }^{+}$ count of less than 200 cells $/ \mathrm{mm}^{3}$ and 75 (35.3\%) had CV HIV-1 higher than 100,000 copies/ml. No statistically significant difference was found between the two periods and the investigated parameters.

Table 1 shows the frequency of individuals co-infected with HIV-1 virus and hepatitis B or C viruses, as well as the number of patients who had at least one AIDS-defining OI. Statistically significant association was only observed for co-infection with HIV-1/Hepatitis C in the pre-HAART era $(P<0.0001)$ and the number of patients with OIs was lower in the HAART period $(P<0.0001)$.

In the pre-HAART period, the occurrence of OI has led to diagnosis of infection by HIV-1 in 22 (33.8\%), out of the 65 patients whereas in the HAART period, such diagnosis was identified in 71 (29.9\%) out of the 237 patients. Comparison showed no significant difference. In the pre-HAART era, there were 76 episodes of OIs, with pulmonary pneumocystosis being the most frequent one, $28.9 \%$ of the cases, followed by tuberculosis (19.8\%), encephalic toxoplasmosis (18.5\%), cryptococcal meningoencephalitis (14.5\%), esophageal candidiasis (11.8\%), intestinal isosporiasis (3.9\%), and cytomegalovirus infection (2.6\%). In the HAART era, there were 159 episodes of OIs, with esophageal candidiasis being the most frequent $22.0 \%$, followed by encephalic toxoplasmosis (19.5\%), tuberculosis (18.9\%), pulmonary pneumocystosis (15.1\%), cryptococcal meningoencephalitis (10.1\%), intestinal isosporiasis (8.2\%), cytomegalovirus infection

Table 1. Presence of HIV-1/HBV, HIV-1/HCV co-infection, defining opportunistics infections in patients admitted at Hospital Escola Emilio Carlos, Catanduva, São Paulo State, Brazil.

\begin{tabular}{cccccc}
\hline Co-infection & $\begin{array}{c}\text { Number of } \\
\text { patients } \\
\text { (Pre-HAA } \\
\text { RT era) }\end{array}$ & $\begin{array}{c}\text { Number of } \\
\text { patients } \\
\text { (HAART } \\
\text { era) }\end{array}$ & $\%$ & P & \\
\hline HIV/HBV & & & & & \\
Yes & $06 / 65$ & 9.2 & $31 / 237$ & 13.1 & 0.18 \\
No & $15 / 65$ & 23.0 & $177 / 237$ & 74.7 & \\
Ignored & $44 / 65$ & 67.8 & $29 / 237$ & 12.2 & \\
HIV/HCV & & & & & \\
Yes & $14 / 65$ & 21.5 & $40 / 237$ & 16.9 & $<0.0001$ \\
No & $07 / 65$ & 10.8 & $169 / 237$ & 71.3 & \\
Ignored & $44 / 65$ & 67.7 & $28 / 237$ & 11.8 & \\
Presence of infection & & & & & \\
Opportunistic infection & & & & & \\
Yes & $46 / 65$ & 70.8 & $89 / 237$ & 37.5 & $<0.0001$ \\
No & $19 / 65$ & 29.2 & $148 / 237$ & 63.5 & \\
\hline
\end{tabular}

$\overline{\mathrm{HIV}}=$ human immunodeficiency virus; $\mathrm{HBV}=$ hepatitis $\mathrm{B}$ virus; $\mathrm{HCV}=$ hepatitis $\mathrm{C}$ virus.
(4.4\%), intestinal cryptosporidiosis (1.2\%), and disseminated histoplasmosis $(0.6 \%)$. Of note pulmonary pneumocystosis, its occurrence was considerably greater in the pre-HAART era $(P=0.01)$. There was no significant difference between the number of OI episodes in the two periods $(P=0.15)$.

Both in the pre-HAART and in the HAART eras, there was a predominance of OIs in individuals with serial count of T CD4 $4^{+}$lymphocytes count of $<200$ cells $/ \mathrm{mm}^{3}$. As for the distribution of OIs according to the HIV-1 viral load no single pattern was detected, and it varied according to the illness. No association was observed between the frequency of OIs and the serial count of $\mathrm{T} \mathrm{CD} 4^{+}$lymphocytes and of the HIV-1 viral load, in the pre-HAART era. On the other hand, in the HAART period there was a significant association between the serial count of T CD4 $4^{+}$ lymphocytes of less than 200 cells $/ \mathrm{mm}^{3}$ and esophageal candidiasis $(P<0.0001)$, pulmonary pneumocystosis $(P<$ $0.0001)$, encephalic toxoplasmosis $(P<0.0001)$, cytomegalovirus infection $(P<0.0001)$, cryptococcal meningoencephalitis $(P<0.0001)$ and tuberculosis $(P=$ 0.004). Intestinal isosporiasis had significant association both with the serial count of $\mathrm{T} \mathrm{CD} 4^{+}$lymphocytes count of $<200$ cells $/ \mathrm{mm}^{3}$ and the count in the 200-350 cells/ $\mathrm{mm}^{3}$ range $(P=0.0003)$. Concerning the distribution of OIs according to the HIV-1 viral load, the presence of esophageal candidiasis and encephalic toxoplasmosis was significantly higher in patients with viral load $>100.000$ copies/ml $(P<0.0001$ and $P=0.02$, respectively). Intestinal isosporiasis and cytomegalovirus infection were more frequent in individuals with viral load $<10,000$ copies/ml $(P<0.0001$, respectively). Cytomegalovirus infection has prevailed in individuals with viral load in the $10.000-100.000$ copies $/ \mathrm{ml}$ range $(P=0.002)$.

In the pre-HAART ( $\mathrm{n}=65$ patients), there were 45 deaths, whereas in the HAART period $(\mathrm{n}=237$ patients) there were 58 patients. Comparison between the two periods indicates that there was a significant reduction in the death rate in HIV-1 infected patients in the HAART era $(P<0.001)$. Table 2 shows the deaths caused by AIDS-defining OIs and patients' survival rate in the pre-HAART and HAART eras. No significant association was detected between death by OI and non-OI $(P=$ $0.69)$. The other causes of death were bacterial pneumonia, acute renal failure, neoplasias, hepatic cirrhosis, firearm wound, cardiopathy and suicide. Tuberculosis, pulmonary pneumocystosis, and cryptococcal meningoencephalitis were the main OIs that caused the death of patients in both periods of the study, though no signifycant association was found between them. Concerning the patients' survival rate, it was defined as the time elapsed from date of diagnosis of HIV-1 infection and the date of death. Considering the deaths caused by all illnesses (OIs and non OI) and those caused only by OI it 
Table 2. Death caused by AIDS defining opportunistic infection and survival rate of patients admitted at the Hospital Escola Emilio Carlos, Catanduva, São Paulo State.

\begin{tabular}{|c|c|c|c|c|c|}
\hline Variables & $\begin{array}{c}\begin{array}{c}\text { Number of } \\
\text { deaths }\end{array} \\
\text { (Pre-HAART) }\end{array}$ & $\%$ & $\begin{array}{c}\text { Number } \\
\text { of deaths } \\
\text { (HAART) }\end{array}$ & $\%$ & $\boldsymbol{P}$ \\
\hline Deaths & & & & & \\
\hline Opportunistic infection & 29/45 & 64.4 & $34 / 58$ & 58.6 & 0.69 \\
\hline Other causes & $16 / 45$ & 35.6 & $24 / 58$ & 41.4 & 0.52 \\
\hline \multicolumn{6}{|l|}{ Opportunistic infection } \\
\hline Tuberculosis & $06 / 29$ & 20.7 & $13 / 34$ & 38.2 & 0.21 \\
\hline $\begin{array}{c}\text { Pulmonary } \\
\text { pneumocystosis }\end{array}$ & $09 / 29$ & 31.0 & $10 / 34$ & 29.5 & 0.89 \\
\hline $\begin{array}{c}\text { Cryptococcal } \\
\text { meningoencephalitis }\end{array}$ & $09 / 29$ & 31.0 & $07 / 34$ & 20.6 & 0.50 \\
\hline $\begin{array}{l}\text { Encephalic } \\
\text { toxoplasmosis }\end{array}$ & $04 / 29$ & 13.8 & $03 / 34$ & 8.8 & 0.82 \\
\hline $\begin{array}{c}\text { Disseminated } \\
\text { histoplasmosis }\end{array}$ & - & - & $01 / 34$ & 2.9 & \\
\hline $\begin{array}{l}\text { Cytomegalovirus } \\
\text { infection }\end{array}$ & $01 / 29$ & 3.5 & - & - & \\
\hline \multicolumn{6}{|l|}{$\begin{array}{c}\text { Survival time } \\
\text { (Deaths by all causes) }\end{array}$} \\
\hline$<1$ year & $24 / 45$ & 53.3 & $36 / 58$ & 62.1 & 0.49 \\
\hline 1 to 3 years & $13 / 45$ & 28.9 & $10 / 58$ & 17.2 & 0.24 \\
\hline$>3$ years & $08 / 45$ & 17.8 & $12 / 58$ & 20.7 & 0.90 \\
\hline \multicolumn{6}{|l|}{$\begin{array}{c}\text { Survival time } \\
\text { (Deaths by } \\
\text { opportunistic infection) }\end{array}$} \\
\hline$<1$ year & $15 / 29$ & 51.7 & $28 / 34$ & 82.2 & 0.01 \\
\hline 1 to 3 years & $09 / 29$ & 31.0 & 03/34 & 8.9 & 0.06 \\
\hline$>3$ years & $05 / 29$ & 17.3 & $03 / 34$ & 8.9 & 0.53 \\
\hline
\end{tabular}

$\mathrm{n}=$ number of samples; HAART $=$ highly active antiretroviral therapy; Conventional sign used - : Numeric data equal to zero are not the result of an approximation.

is found that most individuals showed a survival of $<1$ year in both periods. However, the association between the number of deaths by OI and the survival rate of less than 1 year in the HAART $(P=0.01)$ was significant.

It has not been possible to evaluate non-adherence to treatment in the disease evolution towards death in patients in the pre-HAART era due to the lack of information on the therapeutic treatment in the patients' records. On the other hand, during the HAART era, non-adherence to antiretroviral therapy was reported in 52 (89.7\%) out of the 58 patients who died. Of these, twenty-eight (48.3\%) were given an association of nucleoside analogue reverse transcriptase inhibitors (NRTI) with non-nucleoside analogue reverse transcriptase inhibitors, and thirty patients (51.3\%) were given the NRTI association with protease inhibitors.

\section{Discussion}

HIV-1 infection was predominant in young male indi- viduals in the two study periods. However, there has been a reduction in the ratio of men (M) and women (W) infected during the HAART period (1.49 M:1 F), indicating an increase in the incidence of the disease among women. Similarly to the increased heterosexual transmission and feminization of the epidemic in Brazil $[8,15]$, the present study revealed a significant increase in the infection in women during the HAART era $(P=0.03)$. In fact, there was a considerable growth in HIV-1 heterosexual transmission $(P<0.001)$ in this period, whereas transmission by injectable drugs, which was common in the pre-HAART era [16], has considerably decreased ( $P$ $<0.0001)$. The above data underline the importance of the design and implementation of prevention strategies targeted to the heterosexual population, particularly women, in the study area.

Individuals with lower education are currently the most affected by the disease in Brazil [17]. Interestingly, our data show a significant association between the number of HIV-1 infected individuals and higher education in the HAART period $(P=0.001)$, which has already been observed in a previous assessment in the State of São Paulo [18]. Two hypothesis could explain this fact firstly, like many other locations in Brazil, faces increased use of illegal drugs in many social classes, notably the crack, which might lead unwholesome safe sexual practices [19], and secondary, individuals with higher education, knowing that AIDS is a chronic disease that can be treated without any costs being incurred by the patient, probably believe that it is no longer a life-threatening disease [20,21].

Concerning patient admission, the present study has shown that less patients sought health services in the HAART period to treat HIV-1/AIDS $(P=0.04)$. In a concordance with the Brazilian health care policy, the individual is serologically tested in primary health care units, and, whenever necessary, is referred to specialized health care services for diagnostic confirmation and clinical follow-up [22]. Although increase in the epidemic in rural areas is reported in the Brazilian medical literature [23], our statistics do not reflect this trend.

Analysis of LT CD4 ${ }^{+}$and CV HIV-1 values in the first medical appointment indicates that, in both study periods, approximately $40 \%$ of these patients were admitted to hospital at a late stage of their HIV-1 infection and with high viral loads. This has been more clearly demonstrated when we found that $1 / 3$ of these patients, both eras had at least one OI upon admission. This means that these individuals have taken a long time to seek specialized health services, and many times they were already sick at the time of the first medical appointment. This problem has also been reported in other regions of the country $[11,24]$ and the world $[25,26]$. Many individuals do not test for anti-HIV-1 serology because they do not 
believe they may be infected, or because they fear the results of diagnostic tests and the serious implications of the illness, such as rejection from friends and family, and also the absence of a definite cure for the infection. Besides, due to the similarity of the results found in both study periods, we can affirm that late HIV-1 diagnosis is still a serious and chronic issue in Catanduva, so that priority should be given to the development of prevention programs.

Despite the fact that around one third of the subjects in both study periods have been diagnosed with HIV-1 infection due to the presence of an OI, the number of patients with OIs in this study was significantly lower in the HAART era $(P<0.0001)$. This is consistent with findings of the world medical literature, since HAART promotes control of viremia and immune reconstitution, reducing the rate of complications related to immunodepression $[27,28]$.

Individuals exposed to HIV-1 infection may also acquire the viruses of hepatitis B and C, since these pathogens share the same transmission modes [29]. In the present study, HIV-1/HCV co-infection was significantly higher in the pre-HAART era $(P<0.0001)$, probably because the use of injectable drugs, which was more common at that time [6]. In the HAART era, the prevalence of this co-infection in Brazil has varied according to the region and the type of exposure [30]. As for the analysis of $\mathrm{HIV}-1 / \mathrm{HBV}$ we found that, despite the increased sexual transmission of HIV-1 in the HAART era, the frequency of infection by virus B did not significantly increase in this population.

Surprisingly, despite the significant reduction in the number of patients with OI in the HAART era, no significant decrease in the number of OI episodes was found among the two groups, except for pulmonary pneumocystosis $(P<0.01)$. One possible explanation for these findings is that individuals who take irregular antiretroviral and chemoprophylactic treatment against OIs could have recurrent episodes of these illnesses. On the other hand, patients who take regular antiretroviral therapy may develop the immune reconstitution inflammatory syndrome (IRIS) [31], which can be expressed in a greater number of OI. Unfortunately, due to lack of information on patients' medical records, we could not further investigate these facts.

No association was observed between the frequency of OIs and serial count of T CD4 ${ }^{+}$lymphocytes with HIV-1 viral load in the pre-HAART era. This can be related to the unavailability of tests in the municipality in that period. Nevertheless, the association between the frequency of OIs and severe immunodeficiency (LT CD4 ${ }^{+}<200$ cells $/ \mathrm{mm}^{3}$ ) was evident during the HAART period. It is known that the greater the immunodeficiency generated by $\mathrm{HIV}-1$, the greater the risk of OI occurrence, [32] which was also observed in our study. What is remarkable however about chronic intestinal isosporiasis is that, despite its prevalence being more reported in patients with a count of LT CD4 ${ }^{+}<200$ cells $/ \mathrm{mm}^{3}[33,34]$, in our study it has also shown a significant association with higher $\mathrm{LT} \mathrm{CD}^{+}$ranges $(P=0.0003)$ and with a lower HIV-1 load $(P=0.0001)$. Despite our small sample size, one possible explanation for this fact could be the presence of new strains of Isospora belli that are more adapted to the HIV-1 infected patient, and, causing chronic infection in individuals with less marked immunodepression. On the other hand, since this coccidian is not limited to severe immunodeficiency or to high HIV-1 viral load, it may be interesting to perform diagnostic tests in all HIV-1 infected individuals in Catanduva who present diarrhea, regardless the serial count of $\mathrm{T} \mathrm{CD} 4^{+}$ lymphocytes or the viral load. Indeed, the difficulty of $I$. belli diagnosis is linked to systemic use of trimethoprim and sulfamethoxazole, which is given with low $\mathrm{CD}^{+}$ T-cell counts as a prophylactic treatment of pneumocystosis [35].

It is known that the introduction of the HAART has significantly reduced mortality by OIs in HIV-1/AIDS patients [36]. Nonetheless, there was no significant decrease in the number of deaths by OIs and they still account for most of the deaths that occurred in the two study periods. This indicates that OIs are important causes of death in the municipality of Catanduva, despite the current policy of universal and free administration of HAART and chemoprophylaxis. This fact can be related to the late diagnosis of these illnesses or else because the patient takes too long to seek the specialized health service.

Regarding the OIs that caused death, tuberculosis, pulmonary pneumocystosis, and cryptococcal meningoencephalitis were the most lethal diseases, accounting for more than $80 \%$ of the deaths among all the OIs in both periods. These illnesses have already been reported as a factor that indicates worse prognosis and a greater tendency to cause death among HIV-1/AIDS infected patients [23]. Therefore, investment in diagnosis and early treatment of the OIs should be prioritized in the municipality.

The significant association between the number of deaths by OIs and the low survival period in the HAART era is a matter of great concern, since it indicates that the availability of highly active antiretroviral therapy alone is not sufficient to ensure greater survival to the infected individuals. In fact, factors, such as late diagnosis of HIV-1 infection, atypical clinical manifestations that confuse the identification of some OIs, and low adherence to treatment could explain this negative impact on the survival of the infected individuals [37]. Nevertheless, patients who take proper HAART could also face the 
relentless evolution of AIDS despite taking the antiretroviral therapy [38] or else have lethal clinical manifestations resulting from the IRIS [31].

\section{Conclusion}

Our results indicate that OIs are still important causes of morbid-mortality among HIV-1/AIDS infected patients in the municipality of Catanduva, particularly pulmonary pneumocystosis, tuberculosis, and cryptococcal meningoencephalitis. We are aware that retrospective studies such as ours, which involve the review of patients' medical records, may present some limitations arising from the scarcity or even absence of information. Despite these limitations, the present study shows, for the first time, the clinical and epidemiological profile of a specialized HIV-1/AIDS center in a municipality in the southeastern region of Brazil, which is consistent with the current epidemiology of AIDS in the country.

\section{Acknowledgements}

We want to acknowledge to all individuals enrolled in this study. The authors also thank Dr. Alexandre Macedo for critical review and the team of the Municipal Program of Sexually Transmissible Diseases/AIDS from Catanduva for assistance in obtaining medical record. A.S.J. is a Master student from Faculdade de Medicina de São José do Rio Preto.

\section{REFERENCES}

[1] UNAIDS, “2009 AIDS Epidemic Update,” 2009. http://data.unaids.org/pub/Report/2009/2009_epidemic_u pdate_en.pdf

[2] T. C. Quinn, "HIV Epidemiology and the Effects of Antiviral Therapy on Long-Term Consequences,” AIDS, Vol. 22, Suppl. 3, 2008, pp. S7-S12. doi:10.1097/01.aids.0000327510.68503.e8

[3] C.-H. Yang, Y.-F. Huang, C.-F. Hsiao, et al., "Trends of Mortality and Causes of Death among HIV-Infected Patients in Taiwan, 1984-2005," HIV Medicine, Vol. 9, No. 7, 2008, pp. 535-543. doi:10.1111/j.1468-1293.2008.00600.x

[4] F. Bonnet, C. Lewden, T. May, et al., "Opportunistic Infections as Causes of Death in HIV-Infected Patients in the HAART Era in France," Scandinavian Journal of Infectious Diseases, Vol. 37, No. 6-7, 2005, pp. 482-487. doi:10.1080/00365540510035328

[5] UNAIDS, “AIDS Epidemic Update, 2007-Latin America Regional Summary,” 2008. http:// www.unAIDS.org.

[6] Brazil, Ministry of Health, "Bulletin Epidemiological of Sexually Transmitted Disease Program/AIDS,” Preliminary Version, 2009. http://www.aids.gov.br.

[7] A. M. Brito, E. A. Castilho and C. L. Szwarcwald, "AIDS and HIV Infection in Brazil: A Multifaceted Epidemic," Revista da Sociedade Brasileira de Medicina Tropical,
Vol. 34, No. 2, 2001, pp. 207-217.

[8] M. G. P. Fonseca and F. I. Bastos, “Twenty-Five Years of the AIDS Epidemic in Brazil: Principal Epidemiological Findings, 1980-2005,” Cadernos de Saúde Pública, Vol. 23, Suppl. 3, 2007, pp. S333-S344. doi:10.1590/S0102-311X2007001500002

[9] R. R. Prado and E. A. Castilho, "The Aids Epidemic in the State of São Paulo: Application of the Full Bayesian Space-Time Model” Revista da Sociedade Brasileira de Medicina Tropical, Vol. 42, No. 5, 2009, pp. 537-542.

[10] M. A. Hacker, A. Kaida, R. S. Hogg, et al., "The First Ten Years: Achievements and Challenges of the Brazilian Program of Universal Access to HIV/AIDS Comprehensive Management and Care, 1996-2006,” Cadernos de Saúde Pública, Vol. 23, Suppl. 3, 2008, pp. 345-359. doi:10.1590/S0102-311X2007001500003

[11] L. S. Melo, H. R. Lacerda, E. Campelo, et al., "Survival of AIDS Patients and Characteristics of Those Who Died over Eight Years of Highly Active Antiretroviral Therapy, at a Referral Center in Northeast Brazil," Brazilian Journal of Infectious Diseases, Vol. 12, No. 4, 2008, pp. 6977. doi:10.1590/S1413-86702008000400003

[12] S. L. Souza, P. V. Feitoza, J. R. Araújo, et al., "Causes of Death among Patients with Acquired Immunodeficiency Syndrome Autopsied at the Tropical Medicine Foundation of Amazonas," Revista da Sociedade Brasileira de Medicina Tropical, Vol. 41, No. 3, 2008, pp. 247-251. doi:10.1590/S0037-86822008000300005

[13] E. C. Soares, V. Saraceni, M. Lauria, et al., "Tuberculosis as a Disease Defining Acquired Immunodeficiency Syndrome: Ten Years of Surveillance in Rio de Janeiro, Brazil,” Jornal Brasileiro de Pneumologia, Vol. 32, No. 5, 2006, pp. 444-448. doi:10.1590/S1806-37132006000500012

[14] C. A. Schmaltz, F. M. Sant'Anna, S. C. Neves, et al., "Influence of HIV Infection on Mortality in a Cohort of Patients Treated for Tuberculosis in the Context of Wide Access to HAART, in Rio de Janeiro, Brazil, ” Journal of Acquired Immune Deficiency Syndromes, Vol. 52, No. 5, 2009, pp. 623-628. doi:10.1097/QAI.0b013e3181b31e56

[15] N. J. S. Santos, A. Tayra, S. R. Silva, et al., "Changes in the Profile of the Epidemic and Prospects for Epidemiological Surveillance,” Revista Brasileira de Epidemiologia, Vol. 5, No. 2, 2002, pp. 286-310.

[16] M. A. Hacker, I. C. Leite, A. Renton, et al., "Reconstructing the AIDS Epidemic among Injection Drug Users in Brazil,” Cadernos de Saúde Pública, Vol. 22, No. 4, 2006, pp. 751-760. doi:10.1590/S0102-311X2006000400014

[17] M. G. Fonseca, C. L. Szwarcwald and F. I. Bastos, “A Sociodemographic Analysis of the AIDS Epidemic in Brazil, 1989-1997," Cadernos de Saúde Pública, Vol. 36, No. 6, 2002, pp. 678-685. doi:10.1590/S0034-89102002000700004

[18] State Secretary of the Health of São Paulo, State Program of DST/Aids, "Bulletin Epidemiologist AIDS and DST," 2009. http://www.aids.gov.br/taxonomy/term/2709/all

[19] Brazil, Ministry of Health, "The Politics of the Ministry 
of Health for the Integral Attention to Users of Alcohol and Other Drugs,” 2003.

http://bvsms.saude.gov.br/bvs/publicacoes/pns_alcool_dr ogas.pdf

[20] N. F. Crum, R. H. Riffenburgh, S. Wegner, et al., "Comparisons of Causes of Death and Mortality Rates among HIV-Infected Persons: Analysis of the Pre-, Early, and Late HAART (Highly Active Antiretroviral Therapy) Eras," Journal of Acquired Immune Deficiency Syndromes, Vol. 41, No. 2, 2006, pp. 194-200. doi:10.1097/01.qai.0000179459.31562.16

[21] C. M. Lowndes, F. I. Bastos, K. M. Giffin, et al., "Differential Trends in Mortality from AIDS in Men and Women in Brazil (1984-1995)," AIDS, Vol. 14, No. 9, 2000, pp. 1269-1273. doi:10.1097/00002030-200006160-00025

[22] Brazil, Ministry of Health, "Counseling for STD/HIV in Primary Care,” 2006, http:// www.aids.gov.br

[23] V. Y. Soares, C. E. Lúcio Filho, L. I. Carvalho, et al., "Clinical and Epidemiological Analysis of Patients with HIV/AIDS Admitted to a Reference Hospital in the Northeast Region of Brazil, " Revista do Instituto de Medicina Tropical de São Paulo, Vol. 50, No. 6, 2008, pp. 327-332. doi:10.1590/S0036-46652008000600003

[24] M. S. Sá, J. Sampaio, T. Haguihara, et al., "Clinical and Laboratory Profile of HIV-Positive Patients at the Moment of Diagnosis in Bahia, Brazil,” Brazilian Journal of Infectious Diseases, Vol. 11, No. 4, 2007, pp. 395-398. doi:10.1590/S1413-86702007000400004

[25] S. Schwarcz, L. Hsu, J. W. Dilley, et al., "Late Diagnosis of HIV Infection: Trends, Prevalence, and Characteristics of Persons Whose HIV Diagnosis Occurred within 12 Months of Developing AIDS, " Journal of Acquired Immune Deficiency Syndromes, Vol. 43, No. 4, 2006, pp. 491494. doi:10.1097/01.qai.0000243114.37035.de

[26] K. N. Althoff, S. J. Gange, M. B. Klein, et al., "Late Presentation for Human Immunodeficiency Virus Care in the United States and Canada," Clinical Infectious Diseases, Vol. 50, No. 11, 2010, pp. 1512-1520. doi:10.1086/652650

[27] A. Mocroft, A. N. Phillips, J. Gatell, et al., "Normalisation of CD4 Counts in Patients with HIV-1 Infection and Maximum Virological Suppression Who Are Taking Combination Antiretroviral Therapy: An Observational Cohort Study," The Lancet, Vol. 370, No. 9585, 2007, pp. 407413. doi:10.1016/S0140-6736(07)60948-9

[28] R. Detels, P. Tarwater, J. P. Phair, et al., "Effectiveness of Potent Antiretroviral Therapies on the Incidence of
Opportunistic Infections before and after AIDS Diagnosis”. AIDS, Vol. 15, No. 3, 2001, pp. 347-355. doi:10.1097/00002030-200102160-00008

[29] J. M. Alter, "Epidemiology of Viral Hepatitis and HIV Co-Infection,” Journal of Hepatology, Vol. 44, Suppl. 1, 2006, pp. S6-S9. doi:10.1016/j.jhep.2005.11.004

[30] M. B. Victoria, F. S. Victoria, K. L. Torres, et al., "Epidemiology of HIV/HCV Coinfection in Patients Cared for at the Tropical Medicine Foundation of Amazonas," Brazilian Journal of Infectious Diseases, Vol. 14, No. 2, 2010, pp. 135-140. doi:10.1590/S1413-86702010000200004

[31] M. A. French, "Immune Reconstitution Inflammatory Syndrome: A Reappraisal,” Clinical Infectious Diseases, Vol. 48, No. 1, 2009, pp. 101-107. doi:10.1086/595006

[32] H. C. Lane, "Pathogenesis of HIV Infection: Total CD4 T-Cell Pool, Immune Activation, and Inflammation,” Topics in HIV Medicine, Vol. 18, No. 1, 2010, pp. 2-6.

[33] S. V. Kulkarni, R. Kairon, S. S. Sane, et al., "Opportunistic Parasitic Infections in HIV/AIDS Patients Presenting with Diarrhoea by the Level of Immunesuppression," Indian Journal of Medical Research, Vol. 103, No. 1, 2009, pp. 63-66.

[34] S. Assefa, B. Erko, G. Medhin, et al., "Intestinal Parasitic Infections in Relation to HIV/AIDS Status, Diarrhea and CD4 T-Cell Count,” BMC Infectious Diseases, Vol. 9, 2009, p. 155. doi:10.1186/1471-2334-9-155

[35] A. Ebrahimzadeh and E. J. Bottone, "Persistent Diarrhea Caused by Isopora belli: Therapeutic Response to Pyrimethamine and Sulfadiazine,” Diagnostic Microbiology and Infectious Disease, Vol. 26, No. 2, 1996, pp. 87-89. doi:10.1016/S0732-8893(96)00175-7

[36] F. J. Zhang, Z. H. Dou, Y. Ma, et al., "Five-Year Outcomes of the China National Free Antiretroviral Treatment Program,” Annals of internal medicine, Vol. 151, No. 4, 2009, pp. 241-251.

[37] D. B. Hanna, M. R. Pfeiffer, L. V, Torian, et al., "Concurrent HIV/AIDS Diagnosis Increases the Risk of ShortTerm HIV-Related Death among Persons Newly Diagnosed with AIDS, 2002-2005,” AIDS Patient Care and STDS, Vol. 22, No. 1, 2008, pp. 17-28. doi:10.1089/apc.2007.0042

[38] H. B. Krentz, G. Kliewer and M. J. Gill, “Changing Mortality Rates and Causes of Death for HIV-Infected Individuals Living in Southern Alberta, Canada from 1984 to 2003,” HIV Medicine, Vol. 6, No. 2, 2005, pp. 99-106. doi:10.1111/j.1468-1293.2005.00271.x 